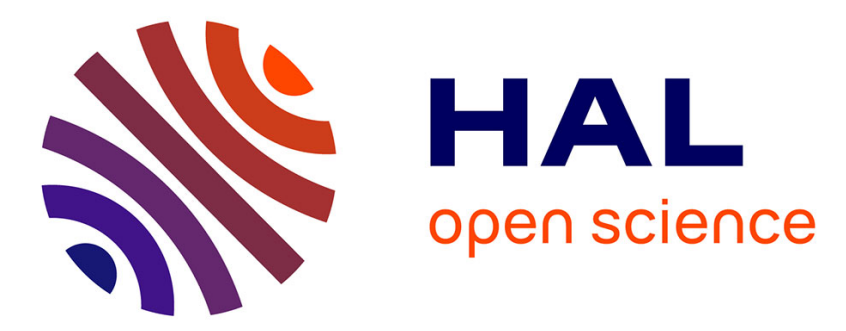

\title{
Transitory powder flow dynamics during emptying of a continuous mixer
}

Chawki Ammarcha, Cendrine Gatumel, Jean-Louis Dirion, Michel Cabassud, Vadim Mizonov, Henri Berthiaux

\section{To cite this version:}

Chawki Ammarcha, Cendrine Gatumel, Jean-Louis Dirion, Michel Cabassud, Vadim Mizonov, et al.. Transitory powder flow dynamics during emptying of a continuous mixer. Chemical Engineering and Processing: Process Intensification, 2013, vol. 65, pp.68-75. 10.1016/j.cep.2012.12.004 . hal00876515

\section{HAL Id: hal-00876515 \\ https://hal.science/hal-00876515}

Submitted on 24 Oct 2013

HAL is a multi-disciplinary open access archive for the deposit and dissemination of scientific research documents, whether they are published or not. The documents may come from teaching and research institutions in France or abroad, or from public or private research centers.
L'archive ouverte pluridisciplinaire HAL, est destinée au dépôt et à la diffusion de documents scientifiques de niveau recherche, publiés ou non, émanant des établissements d'enseignement et de recherche français ou étrangers, des laboratoires publics ou privés. 


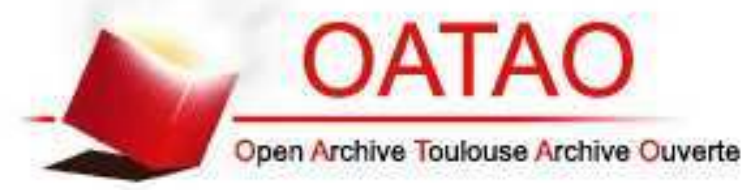

This is an author-deposited version published in : http://oatao.univ-toulouse.fr/ Eprints ID : 9910

To link to this article : DOI:10.1016/j.cep.2012.12.004

URL : http://dx.doi.org/10.1016/j.cep.2012.12.004

To cite this version :

Ammarcha, Chawki and Gatumel, Cendrine and Dirion, JeanLouis and Cabassud, Michel and Mizonov, Vadim and Berthiaux, Henri Transitory powder flow dynamics during emptying of a continuous mixer. (2013) Chemical Engineering and Processing : Process Intensification, vol. 65 . pp. 68-75. ISSN 0255-2701

Any correspondence concerning this service should be sent to the repository administrator: staff-oatao@ listes.diff.inp-toulouse.fr 


\title{
Transitory powder flow dynamics during emptying of a continuous mixer
}

\author{
C. Ammarcha a , C. Gatumel ${ }^{\mathrm{a}}$, J.L. Dirion ${ }^{\mathrm{a}}$, M. Cabassud ${ }^{\mathrm{b}}$, V. Mizonov ${ }^{\mathrm{c}}$, H. Berthiaux ${ }^{\mathrm{a}, *}$ \\ a Centre RAPSODEE, FRE CNRS, Ecole des Mines d'Albi-Carmaux, Campus Jarlard, route de Teillet, 81000 Albi, France \\ b Laboratoire de Génie Chimique, UMR 5503 CNRS-INPT-UPS, BP 1301, 5 rue Paulin Talabot, 31106 Toulouse, France \\ ' Ivanovo State Power Engineering University, Department of Applied Mathematics, Rabfakoskaya 34, 153003 Ivanovo, Russia
}

Keywords:

Semi-batch mixing

Powder

Markov chain

Transitory regime

\begin{abstract}
A B S T R A C T
This article investigates the emptying process of a continuous powder mixer, from both experimental and modelling points of view. The apparatus used in this work is a pilot scale commercial mixer Gericke GCM500, for which a specific experimental protocol has been developed to determine the hold up in the mixer and the real outflow. We demonstrate that the dynamics of the process is governed by the rotational speed of the stirrer, as it fixes characteristic values of the hold-up weight, such as a threshold hold-up weight. This is integrated into a Markov chain matrix representation that can predict the evolution of the hold-up weight, as well as that of the outflow rate during emptying the mixer. Depending on the advancement of the process, the Markov chain must be considered as non-homogeneous. The comparison of model results with experimental data not used in the estimation procedure of the parameters contributes to validating the viability of this model. In particular, we report results obtained when emptying the mixer at variable rotational speed, through step changes.
\end{abstract}

\section{A quick state-of-the-art}

The mixing of solids is a common operation in several industrial applications. It frequently represents a crucial unit operation in many industries (foodstuffs, cosmetics, ceramics, detergents, powdered metals, plastics, drugs, etc.). While mixers are operated either in batch or in continuous mode for industrial applications, it is current to see such machines operating in semi-batch mode during limited periods of time, either because the feed has been stopped while keeping a continuous withdrawal, or conversely keeping a continuous feed with a blocked outlet. This has been recently pointed out by Berthiaux et al. [4], who studied the impact of feeding perturbations on mixture quality for an OTC drug. Because loss-in-weight feeders loose their regularity when the mass of powder in the hopper becomes less than approximately $15-20 \%$ of its apparent volume, the filling period of the feeders results in an important source of mixture heterogeneity. It was suggested to stop the feeders when filling and operate the continuous mixer in semi-batch mode, at least not to disturb the following operations like tabletting. Another example of the importance of semi-batch mode in the industry is the discharge of batch blenders at the end of operation. During emptying, the batch mixer is therefore transformed into a semi-batch system. In the case of batch convective mixers, it is worth noting that operators will run the engine at high

\footnotetext{
* Corresponding author. Tel.: +33 563493144.

E-mail addresses: henri.berthiaux@mines-albi.fr, henri.berthiaux@mines-albi.fr (H. Berthiaux).
}

speed to accelerate the emptying process without paying attention to the effect this procedure can have on mixture quality. In the pharmaceutical industry, this is all the more important because of the "principle of reconciliation" stating that each portion of each material should be tracked from its entering into the system to its leaving.

If we exclude the paper by Sudah et al. [13], very few studies have been published concerning the emptying process of a mixer and its effect on blend homogeneity or powder flow. More generally, continuous processing of powders has never been extensively studied from the viewpoint of transitory regime phases that are currently taking place during emptying, starting or dosage mode changing. This is all the more astonishing that the discrete nature of granular media logically induces transitory motion and transitory flow.

Behaviour of granular materials in mixers or in other process equipment, is still poorly understood from a fundamental standpoint, as it is hardly possible to portray perfectly all the details of the process in a mathematical form and in a reasonable time. However, some dynamic models are present in the chemical engineering literature, trying to explain and describe globally the process rather than into full details. Markov chains pertain to this system's approach toolbox.

Two cases are underlined behind the term mixing and must be distinguished when dealing with models of any type: bulk particle flow and transport in any type of vessel, including in mixers; mixing/blending of various flows related to different types of particle [3]. Several researchers used the Markov chain theory to describe "pure" powder flow patterns in mixers. Some 40 years ago, Inoue and Yamaguchi [8] described the general flow pattern of glass beads 
inside a batch tumbler mixer. A single coloured bead was added and its position was recorded at every transition (revolution of the mixer). The experimental data were used to determine the transition matrix, and served to derive a two dimensional homogeneous Markov chain model. More recently, Aoun et al. [1] applied this type of model for a laboratory hoop mixer, which was divided into 33 elementary cells (11 axial compartments that were in turn separated into 3 radial cells). The experimental data allowed to derive the transition matrix and served again to diagnose the flow pattern of couscous particles in the vessel. Other examples of Markov chains for the description of powder flow in mixers can be found in Chen et al. [5] and Lai and Fan [9].

At the very same time, other researchers were modelling the mixing of different particulate flows, principally binary mixtures. At the end of the seventies, Fan and Shin [7] studied the binary mixing process of spherical lucite particles with two different particle size in a tumbler mixer divided into 10 sections of equal volume. They linked the transition probabilities of a Markov chain to the diffusion coefficient and the drift velocity. The transition matrix was determined experimentally and allowed to describe the concentration profiles for each system. More recently, a two-dimensional model of the flow and mixing of particulate solids has been developed on the basis of the Markov chain theory for an alternately revolving static mixer [12]. This model represented the distribution of component during mixing operation, in both vertical and horizontal directions. Several simulations were performed to investigate the effect of the initial loading of the components, and the effect of the values of the transition probabilities. Other examples are published in Oyama and Agaki [11], Wang and Fan [14] or Wang and Fan [15].

In the present article, we will concentrate on studying the discharge process of a continuous pilot-scale convective mixer. We will focus on the effect of the initial powder mass, as well as on the rotational speed of the stirrer while emptying the mixer on both the hold-up weight of a "pure" bulk material and its outlet flow rate. This is a preliminary to a better understanding of the dynamics of blend discharging and its impact on mixture homogeneity. We will also investigate the effect of step variations in the rotational stirrer's speed during emptying of the mixer. All this will be integrated into a Markov chain as a tool for prediction of hold-up weight and outflow rate from operating variables values and variability.

\section{Experimental set-ups and methods}

The experiments were performed in a Gericke GCM 500 continuous pilot scale powder mixer, which can be run either in continuous, batch or semi-batch mode. This mixer is equipped with three lossin-weight feeders to ensure a very precise and regular dosage. In this work, all experiments were performed in semi-batch mode, which means that particles have been initially placed in the blender and feeders were not used. At the outlet of the mixer an analytical balance is placed to measure the outflow mass in real time. This balance communicates with a computer through a serial port RS232 we have configured in the Matlab Control Toolbox. Therefore all data are measured and saved in real time. Experiments have been performed with food products, namely couscous particles. Full description of equipment and powder used can be seen in Marikh et al. [10] and in Fig. 1a. The mixer itself is a hemi-cylindrical tank of $50 \mathrm{~cm}$ long, $16.5 \mathrm{~cm}$ height and $20 \mathrm{~cm}$ diameter. Particle motion is due to the stirring action of the mobile, so this mixer can be classified into the category of convective mixers. The stirrer is constituted of 14 rectangular paddles inclined at a $45^{\circ}$ angle and installed on a frame supporting an internal screw. The dimensions of this frame are $45 \mathrm{~cm}$ length and $18 \mathrm{~cm}$ width. The screw is placed at the centre of the frame and allows a convective axial motion of the particles inside the vessel.
The outlet of the mixer consists in a gate valve whose position plays an important role as it determines the section through which particles have to flow out of the apparatus. If this section is reduced, the hold up in the mixer will be higher for fixed conditions, as less particles are allowed to exit from the mixer. In the present work, all experiments have been performed with the outlet gate valve at the maximum of opening. In semi-batch mode, the hold up weight $M_{1}$ is a function influenced a priori by the stirrer's speed of rotation $N_{\mathrm{m}}$ and the initial loading mass (see Fig. 1b). In this study the effect of these variables on the hold up $M_{1}$ will be examined for the following ranges:

- five values of the rotational speed of the mobile $N_{\mathrm{m}}$, which can be expressed by the frequency of the engine, $N$ : 10,20,30, 40 and $50 \mathrm{~Hz}$;

- three initial masses introduced 4, 6 and $8 \mathrm{~kg}$.

The relationship between the rotational speed of the mobile $N_{\mathrm{m}}$ and the frequency of the engine is given by: $N_{\mathrm{m}}(\mathrm{rpm})=2.6 \mathrm{~N}(\mathrm{~Hz})$.

\section{Markov chain modelling of the semi-batch process}

\subsection{General architecture of the model}

The essence of a Markov chain model is that if the present states of a system are known-for example the powder mass in each state-and if the probabilities-for example flow rate ratios-to transit to any other states are also given, then the future state of the system can be predicted. When probabilities are unchanged, the chain is said to be homogeneous and a simple matrix relation can be derived to link the future states to the initial state. Conversely, time-dependent or state-dependent probabilities will result in a step-by-step calculation of the states of the system.

When applied to mixing, the general principle lays in dividing a vessel into $n$ cells (Fig. 2), or states of the system, and to examine the possible transitions of a particle property (mass or concentration in a key component) between each cells during a fixed time interval $\Delta t$.

Let the property under observation be the mass $M_{n}(t)$ of particles in cell $n$ at time $t$, and let $\mathbf{M}(\mathbf{t})$ be the vector of elements $M_{n}(t)$. After each transition, a particle can transit to another cell and the observed property can change in each cell. This is summarised by a $(n \times n)$ matrix $\mathbf{P}(\mathbf{t})$ of transition probabilities, the $p_{j, k}(t)$ corresponding to the transition from state $k$ to state $j$ at time $t$. If we assume that transitions can only occur from one cell to a neighbouring cell, the future state $\mathbf{M}(\mathbf{t}+\boldsymbol{\Delta} \mathbf{t})$ can be predicted by the following matrix equation:

$\mathbf{M}(\mathbf{t}+\Delta \mathbf{t})=\mathbf{P}(\mathbf{t}) \mathbf{M}(\mathbf{t})$

$P(t)=\left(\begin{array}{ccccccc}P_{1,1}(t) & P_{1,2}(t) & \ldots & \ldots & 0 & 0 & 0 \\ P_{2,1}(t) & P_{2,2}(t) & \ldots & \ldots & 0 & 0 & 0 \\ 0 & P_{3,2}(t) & \ldots & \ldots & 0 & 0 & 0 \\ \ldots & 0 & \ldots & P_{i-1, i}(t) & \ldots & \ldots & \ldots \\ \ldots & \ldots & \ldots & P_{i, i}(t) & \ldots & \ldots & \ldots \\ \ldots & \ldots & \ldots & P_{i+1, i}(t) & \ldots & \ldots & \ldots \\ 0 & 0 & \ldots & \ldots & \ldots & P_{n-2, n-1}(t) & 0 \\ 0 & 0 & \ldots & \ldots & \ldots & P_{n-1, n-1}(t) & 0 \\ 0 & 0 & \ldots & \ldots & 0 & P_{n, n-1}(t) & 1\end{array}\right)$

The representation of this procedure under matrix form, gives a practical description and an easy handling of the process dynamics 


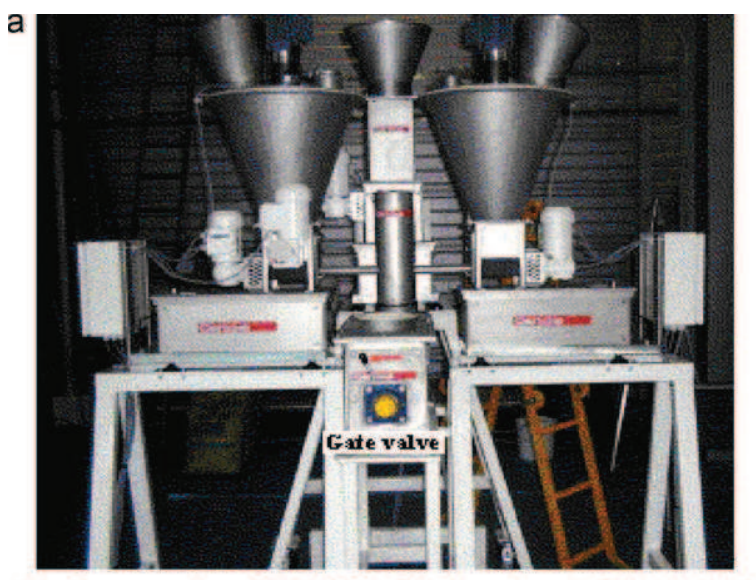

Continuous mix er GCM 500 with three loss-in-Weight feeders

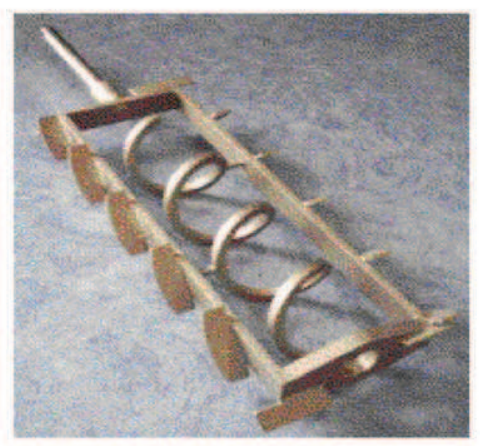

Stirring device

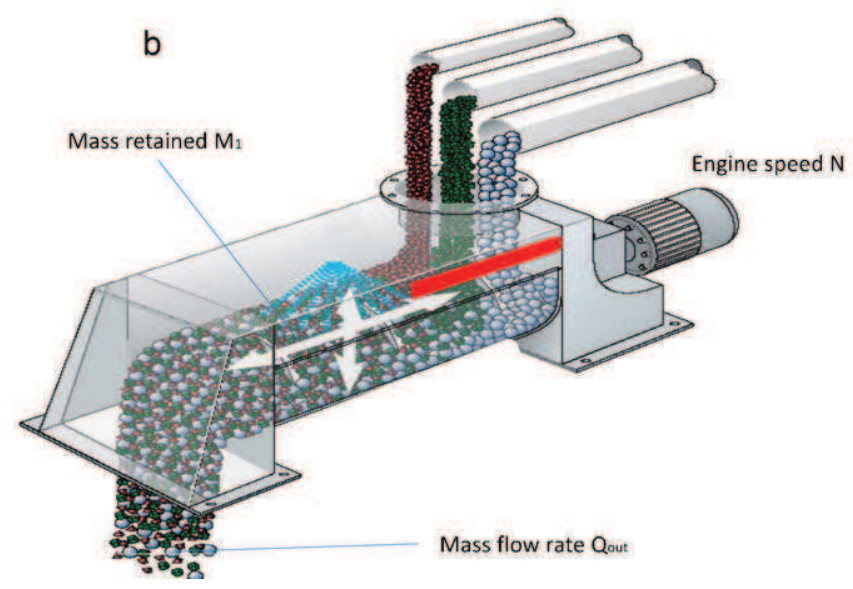

Fig. 1. Gericke GCM500 equipment showing the stirring mobile (a). General process variables (b).

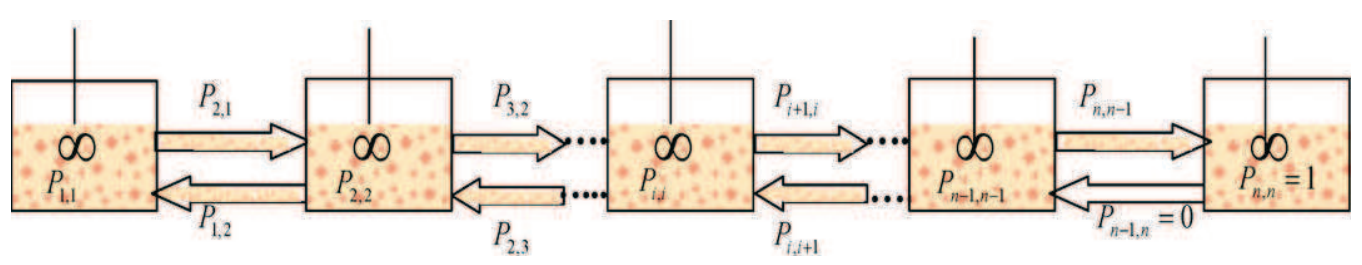

Fig. 2. General Markov chain representation of the semi-batch operation of the mixer, including a flow model inside the mixer.

whatever the regime considered: batch, continuous, semi-batch, multiple staged feed, transitory feed, etc. Full description of blending modelling using Markov chains is detailed in the work by Berthiaux et al. [2].

As aforementioned, the mixer is usually divided into several cells. In the present representation, we will only concentrate on a general frame for modelling able to give information on the "black box" behaviour of the mixer under unsteady conditions, and use a simplified Markov chain model with only two cells. This first model will be implemented in the future to enter into more details of the flow structure, up to the level of the particles through distinct element modelling (DEM), giving then rise to a hybrid model such as the one recently developed by Doucet et al. [6].

The first cell represents the whole mixer, the level of discretisation being the whole apparatus. The second cell is the outlet of the mixer, acting as an absorbing state. This cell is shown, for example, in Fig. 3 as the last cell on the right. If a particle reaches the absorbing state, it stays in it forever, i.e., $p_{i i}=1$ exists for this state. In our case, the absorbing state is joined to the chain artificially.

Let $M_{1}$ be the mass of particles in mixer (or in cell 1 ), and $M_{2}$ the mass of particles in the absorbing state (or in cell 2). The transition of a particle from state 1 to state 2 will obey to the general Markov chain relation:

$$
\begin{aligned}
\left(\begin{array}{l}
M_{1}(t+\Delta t) \\
M_{2}(t+\Delta t)
\end{array}\right) & =\left(\begin{array}{ll}
p_{11}(t) & p_{12}(t) \\
p_{21}(t) & p_{22}(t)
\end{array}\right) \times\left(\begin{array}{l}
M_{1}(t) \\
M_{2}(t)
\end{array}\right) \\
& =\left(\begin{array}{cc}
1-p_{21}(t) & 0 \\
p_{21}(t) & 1
\end{array}\right) \times\left(\begin{array}{l}
M_{1}(t) \\
M_{2}(t)
\end{array}\right)
\end{aligned}
$$

In order to represent the emptying process through Eq. (2), it is necessary to know the initial loading mass $M_{1}(0)$. As the absorbing state does not contain particles initially, then $M_{2}(0)$ is equal to zero. Before running the chain, we must also identify the value of $p_{21}$. This 


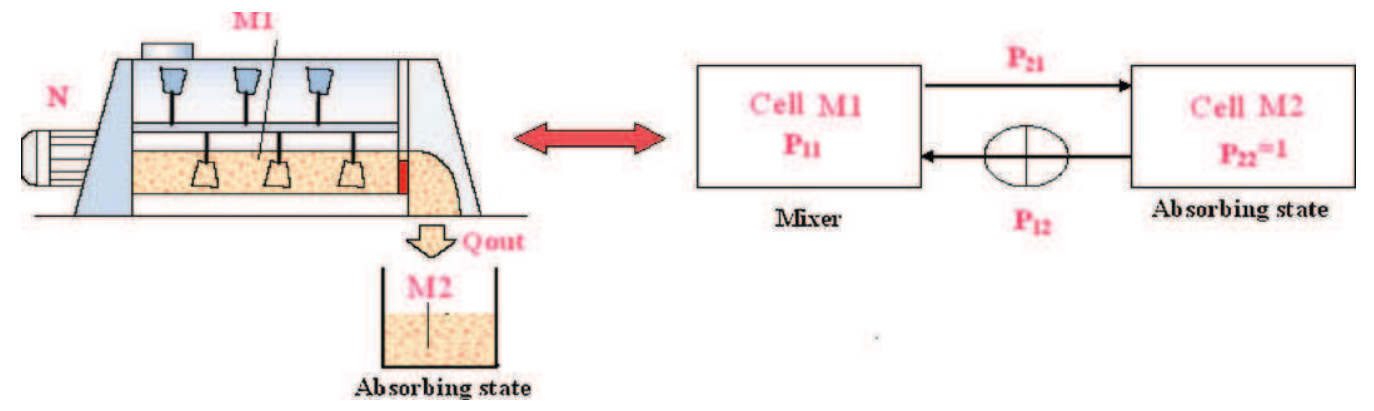

Fig. 3. Simplified Makov chain representation of the emptying process of the mixer.

can be done by the following step-by-step procedure:

$$
\begin{aligned}
P_{21}(t+\Delta t) & =\frac{M_{2}(t+\Delta t)-M_{2}(t)}{M_{1}(t)} \\
& =\frac{\left[M_{1}(0)-M_{1}(t+\Delta t)\right]-\left[M_{1}(0)-M_{1}(t)\right]}{M_{1}(t)}
\end{aligned}
$$

\subsection{Implementing the model from experimental results}

As stated by Eq. (3), $p_{21}(t)$ can be determined from the experimental results of $M_{1}(t)$. Fig. 4 gives an example of the experimental results obtained at $N=20 \mathrm{~Hz}$ for the evolution of the hold-up weight in cell 1 (mixer) for different initial weight. $P_{21}$ is also presented in the same graph for a transition time $\Delta t=1.6 \mathrm{~s}$. This transition time has been arbitrarily fixed after several tries, to ensure a sufficient resolution of the model. Two other similar examples are shown in Fig. 5 for higher rotational speeds. It can be seen that the initial mass $M_{1}(0)$ do not affect the result of probability $p_{21}$, which means that the dynamics of emptying of the mixer only depends on the rotational speed. When examining these results, we can define three regimes of probability corresponding to the current hold up weight in the mixer. There exists a minimum hold up below which no powder can flow out of the mixer, and a threshold value above which $p_{21}$ is constant (and equals $p_{21 \max }$ ). Let $M_{\min }$ and $M_{\text {threshold }}$ be these characteristic hold ups. In terms of transition probability, we have

for $M_{1}>M_{\text {threshold }}, \quad p_{21}=p_{21 \max }$

and for $M_{1}<M_{\min }, \quad p_{21}=0$

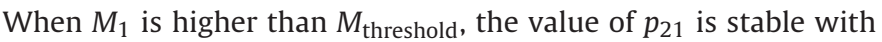
time, so that the Markov chain is a time homogeneous chain or a Markov chains with time-homogeneous transition probabilities. The transition matrix $P$ always remains the same at each step, so the $k$-step transition probability can be computed as the $k^{\prime}$ th power of the transition matrix, $P^{k}$.

When the mass $M_{1}$ is lower than $M_{\text {threshold }}$ and higher than $M_{\min }$, the probability $P_{21}$ increases almost linearly with hold-up weight $M_{1}$ :

for $M_{\min }<M_{1}<M_{\text {threshold }}, \quad p_{21}(t)=a M_{1}(t)+b 0$

In this case, the probability of transition in a single step from state 1 to state 2 depends on the particle mass in state 1 , which makes the transitions time-dependent through its state-dependency. The

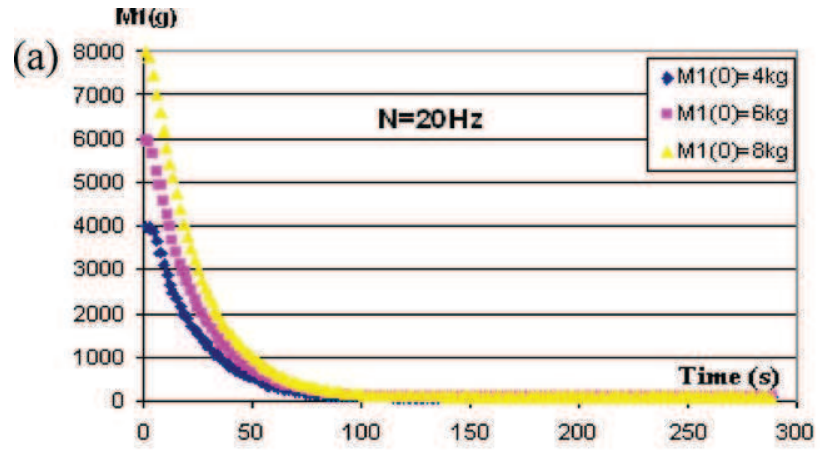

(b)

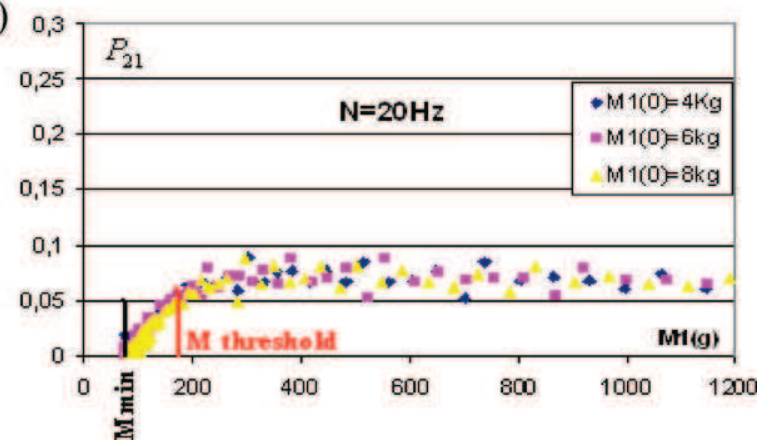

Fig. 4. Experimental evolution of $M_{1}$ and $p_{21}$ during emptying of the mixer $(N=20 \mathrm{~Hz})$.

(a)

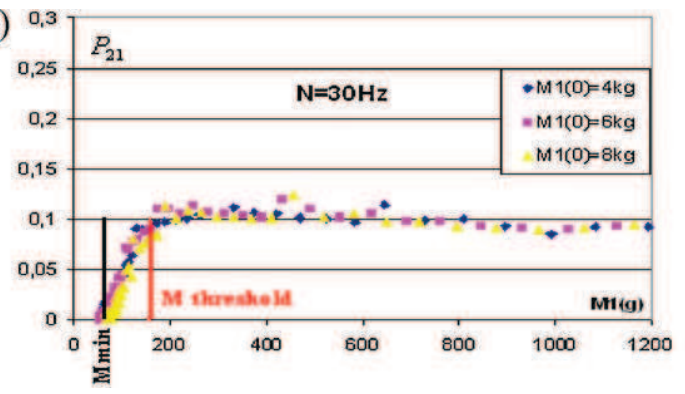

(b)

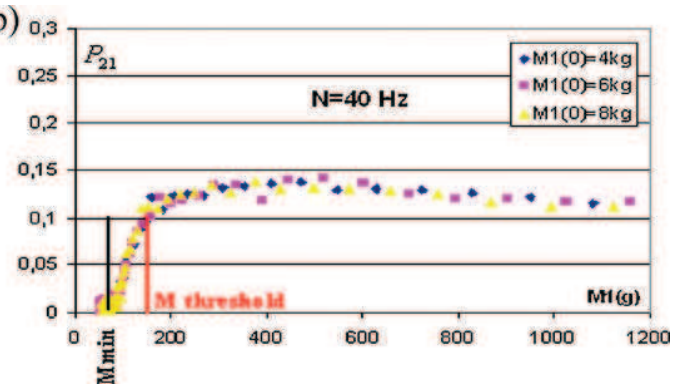

Fig. 5. Experimental evolution of $p_{21}$ during emptying of the mixer at different rotational speeds. 

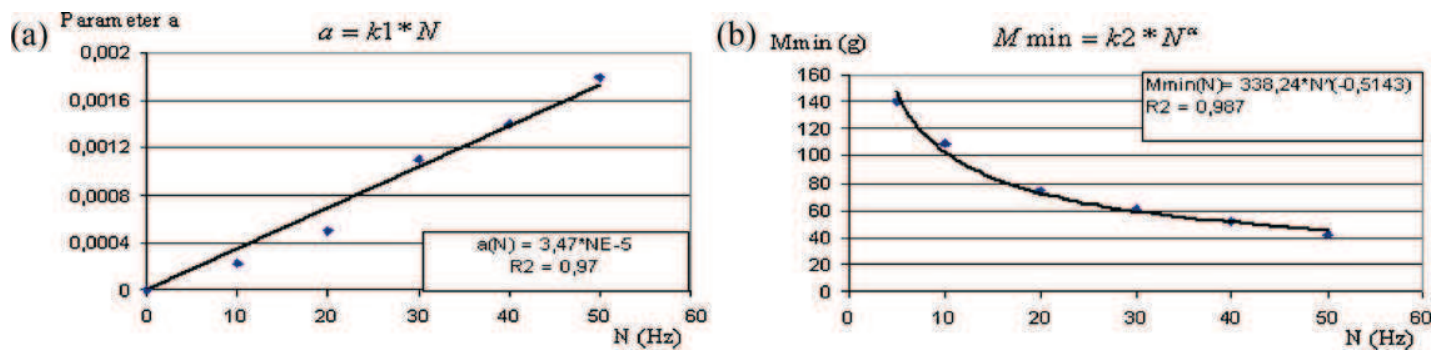

Fig. 6. Evidence of a linear relation between parameter $a$ and $N(\mathrm{a})$; relation between $M_{\min }$ and $N(\mathrm{~b})$.

Markov chain is therefore not homogeneous, and states must be calculated step-by-step. However, this is far from being a problem from a computational point of view. As far as $M_{1}$ is inferior to $M_{\text {threshold }}$, the new probability $p_{21}(t)$ depends only on the previous calculation of the states through $M_{1}(t)$ and both parameters ( $a$ and b) of linear Eq. (6).

Parameter $a$ only depends on the rotational speed $N$ as it can be seen in Fig. 6a, and the second parameter $b$ can be calculated for $M_{1}=M_{\min }$ as $b=-a \times M_{\min }$. In turn, $M_{\min }$ has been related to $N$ through a power law, as indicated in Fig. $6 \mathrm{~b}$. The power has been identified to be closed to 0.5 , so that we considered this value as been fixed and recalculate the other parameter values $k_{1}$ and $k_{2}$ :

$a=k_{1} \times N$

$b=-a \times M_{\min }=-k_{1} \times k_{2} N^{0.5}$

In this non-linear regime, the emptying process of the mixer therefore varies with the hold-up weight and the rotational speed of the mobile through the following general relationship that includes two constants determined form the whole set of experimental data:

$p_{21}(t)=k_{1} N\left(M_{1}(t)-\frac{k_{2}}{\sqrt{N}}\right)$

It must be emphasized that this latter equation makes the overall Markov chain non-homogeneous, as the transition probability depends on the state of the system. If there is no a priori obvious physical explanation for this, it is clear that from a process standpoint, this behaviour must be known to monitor the process.

If $M_{1}$ is higher to $M_{\text {threshold }}$, the probability $p_{21}$ becomes steady and can be linearly related to $N$, as shown in Fig. 7a:

$p_{21 \max }=k_{3} \times N$

Finally, the threshold mass $M_{\text {threshold }}$ can be determined from the above procedure and linked to the rotational speed:

$$
\begin{aligned}
& a \times M_{\text {threshold }}+b=p_{21 \text { max }} \\
& k_{1} \times N \times M_{\text {threshold }}+\left(-k_{1} \times N \times k_{2} \times N^{0.5}\right)=k_{3} \times N \\
& M_{\text {threshold }}=\frac{\left(k_{3}+k_{1} \times k_{2} \times N^{0.5}\right)}{k_{1}}
\end{aligned}
$$

(a)

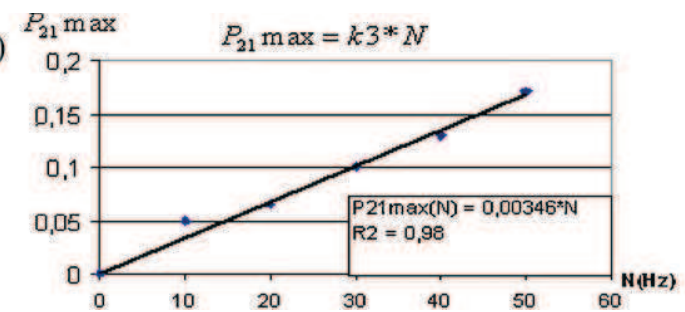

\section{Results and discussion}

Despite the fact that the above model has been developed using a general framework, it contains unknown parameters that have been found from the experiments described in the previous section. In this section, we will test the validity of this procedure by either considering the ability of the model to describe secondary variables, such as outflow rate, or operate the mixer under conditions far from those under which parameters have been obtained, like during step-like perturbations.

\subsection{Predicting outlet flow rate during emptying}

For the product selected, e.g., a free-flowing material, the rotational speed of the stirrer completely defines the dynamics of the emptying process of the mixer by fixing the value of the threshold hold-up weight. Below this value, a non-homogeneous chain can be employed. Above it, a homogeneous chain gives the rule of semi-batch processing. This procedure also gives full access to the evolution of the outlet flow rate $Q_{\text {out }}$, through the following:

$Q_{\text {out }}(t)=\frac{M_{2}(t+\Delta t)-M_{2}(t)}{\Delta t}$

As $M_{2}(t+\Delta t)=M_{2}(t)+p_{21}(t) \times M_{1}(t)$

Qout can then be linked to $p_{21}$ :

$Q_{\text {out }}(t)=\frac{p_{21}(t)}{\Delta t} \times M_{1}(t)$

An example of comparison between experimental results of the flow rate, obtained by Eq. (14), and model simulation form the Markov chain representation is shown in Fig. 8 for different rotational speeds of the stirrer. The different flow regimes, depending on the value of the actual hold-up weight as compared to the threshold value, are again pointed out:

$$
\begin{aligned}
- \text { For } M_{1} & >M_{\text {threshold }} \\
Q_{\text {out }}(t) & =\frac{p_{21 \text { max }}}{\Delta t} M_{1}(t) \\
Q_{\text {out }}(t) & =\frac{k_{3} \times N}{\Delta t} M_{1}(t)
\end{aligned}
$$

(b)

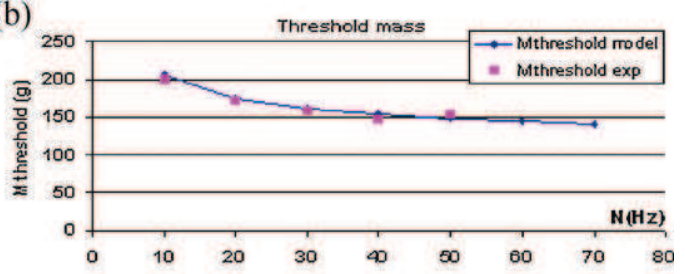

Fig. 7. Derivation of correlations between $p_{21 \max }$ and $N(\mathrm{a})$, and between threshold hold up and $N(\mathrm{~b})$. 

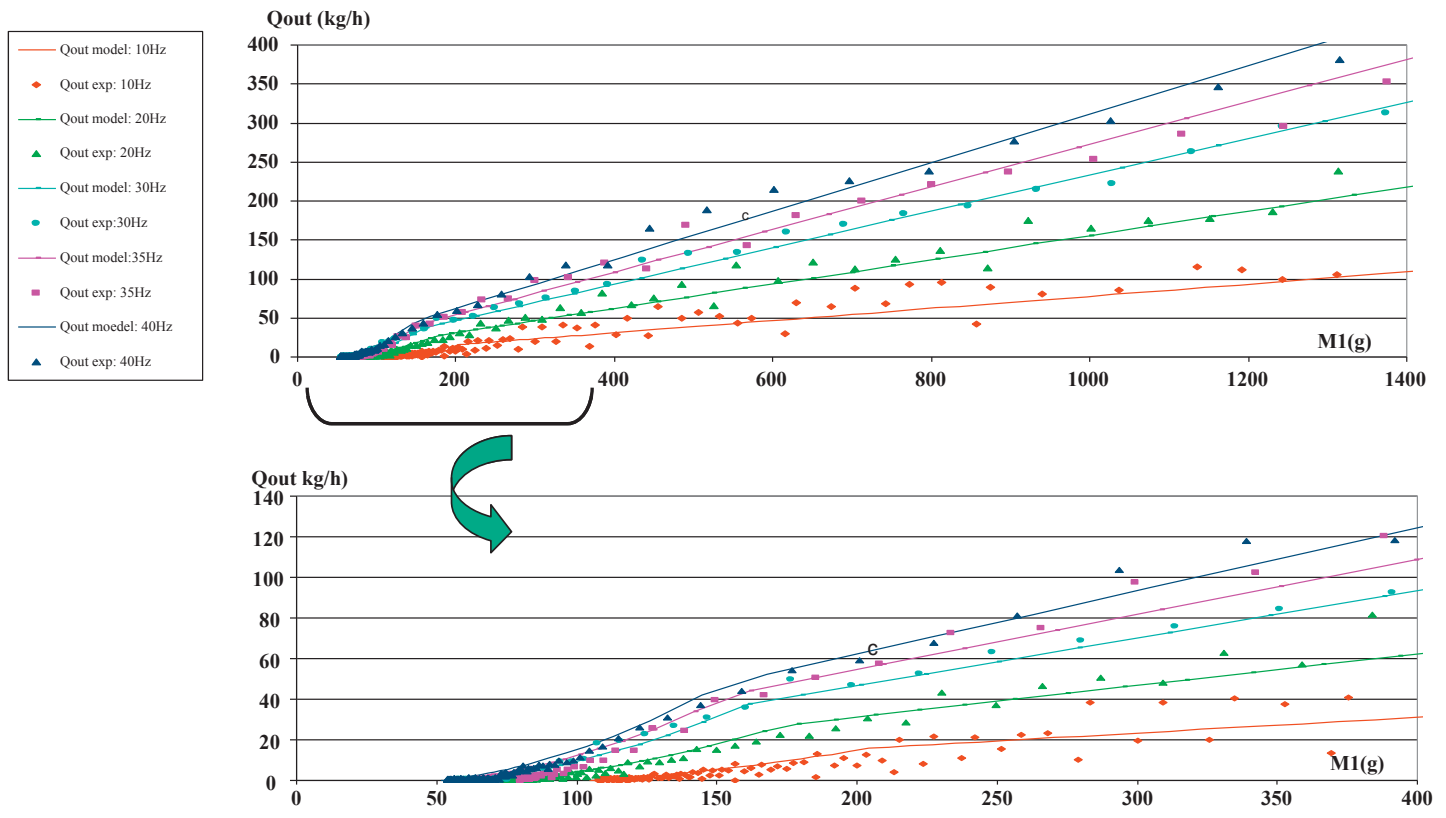

Fig. 8. Comparison of simulated and measured outflow rate according to retained mass $M_{1}$.

$$
\begin{aligned}
- \text { For } M_{\text {min }}<M_{1}<M_{\text {threshold }} \\
\begin{aligned}
Q_{\text {out }}(t) & =\frac{p_{21}(t)}{\Delta t} M_{1}(t) \\
Q_{\text {out }}(t) & =\frac{k_{1} \times N}{\Delta t}\left(M_{1}^{2}(t)-M_{\min } \times M_{1}(t)\right)
\end{aligned}
\end{aligned}
$$

In this latter case, as the transition probability changes linearly with $M_{1}$, the outflow rate increases with the hold-up weight according to a second order polynomial law.

\subsection{Predicting the effect of step-like perturbations}

The predictability of the model can be better demonstrated if its results are plotted against data that have not been used in the determination of its parameters. In this last part, we will compare model results and experimental data obtained when emptying the mixer through negative or positive steps on the rotational speed, as it may be the case in the industry.

Fig. 9 reports the results obtained while changing instantaneously the rotational speed from 20 to $40 \mathrm{~Hz}$ during an emptying process. As it can be observed, the prediction of both outflow rate
Qout and hold up weight $M_{1}$ is excellent when compared to the experimental data. The step in rotational speed induces a jump in flow rate, but a light decrease in hold-up. This is validated experimentally for a wide range of rotational speed of the stirrer device $(10-50 \mathrm{~Hz})$, not reported here for clarity. Another example of comparison is shown in Fig. 10, for which a negative step change in the rotational speed from 35 to $15 \mathrm{~Hz}$ has been performed. The same conclusions can be drawn on the model's performance.

The evolution of the outflow rate with the hold up weigh $M_{1}$ during these two types of perturbation is shown in Fig. 11. The lines predicted by the model with or without perturbation are also figured to better illustrate the effect of the step changes.

The transition probabilities, used in these simulations, are determined from the empirical equations (4)-(6), and are represented in Fig. 12 for the positive step. In this graph, we can differentiate three phases depending on $N$ and $M_{1}$ (see Fig. 13 for a representation in terms of outflow rate):

- Initially, $N$ is fixed at $20 \mathrm{~Hz}$. In this case, as the hold-up weight in the mixer $M_{1}$ is higher than $M_{\text {threshold }}$, the value of $p_{21}$ is stable (a)

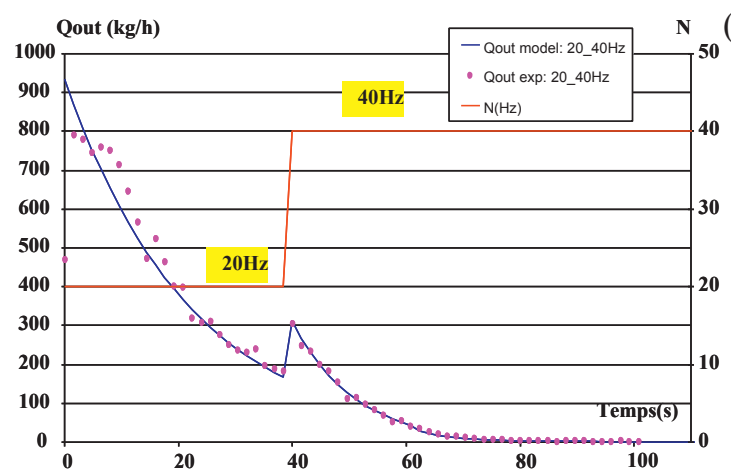

(b)

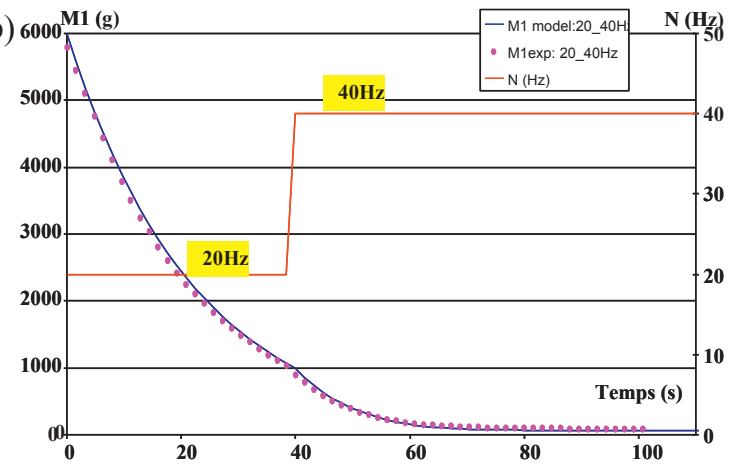

Fig. 9. Comparison of simulated and measured results during emptying with a positive step change in rotational speed ( $N=20-40 \mathrm{~Hz}$ ). Effect on the outflow rate (a) and on the hold up weight (b). 
(a)

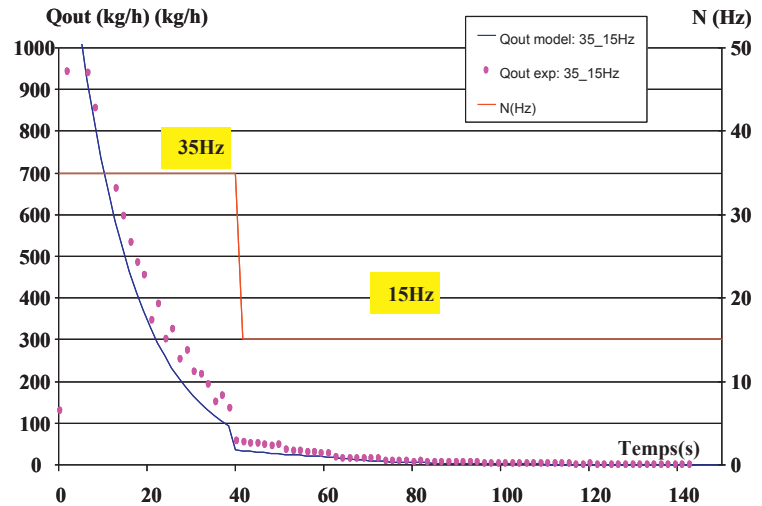

(b)

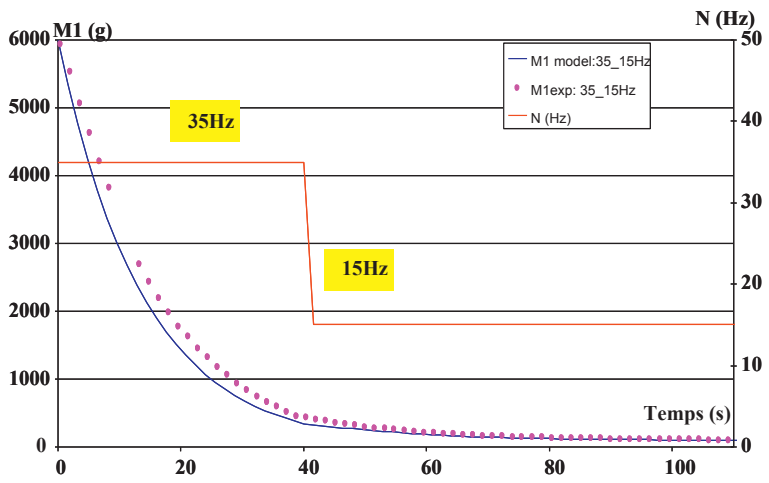

Fig. 10. Comparison of simulated and measured results during emptying with a negative step change in rotational speed $(N=35-15 \mathrm{~Hz})$. Effect on the outflow rate (a) and on the hold up weight (b).

(a)

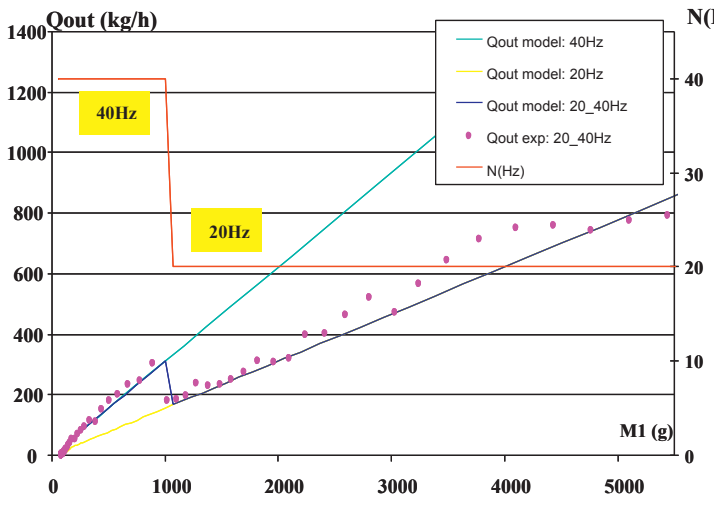

(b)

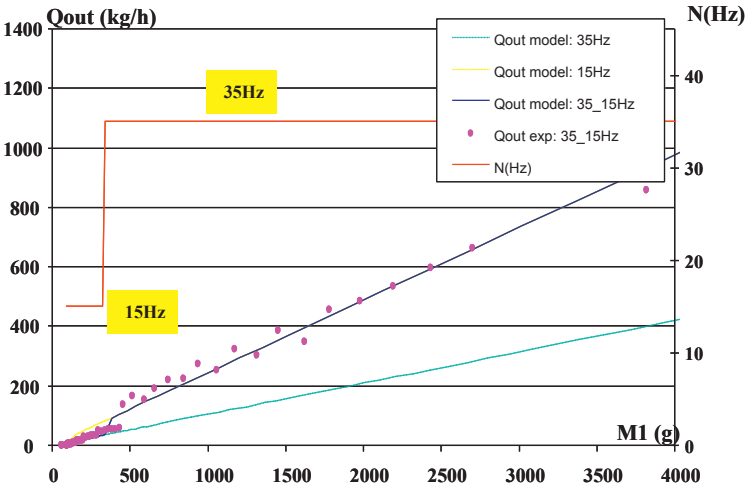

Fig. 11. Evolution of the outflow rate according to hold-up weight after a positive (a) and or a negative (b) step change in rotational speed $N$.

(a)

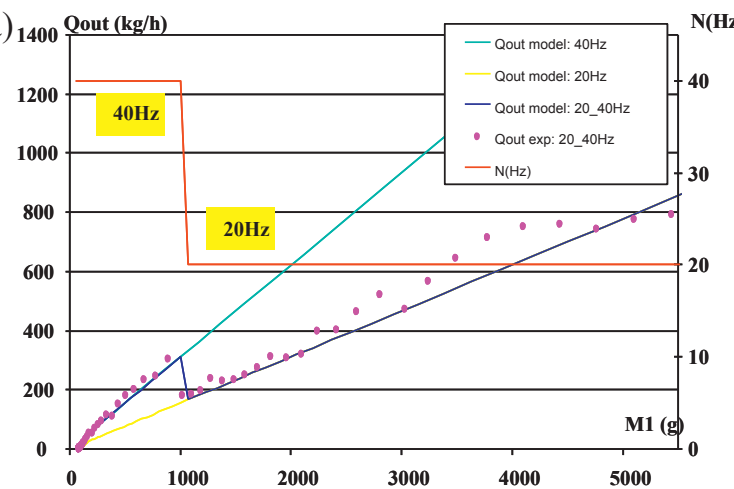

(b)

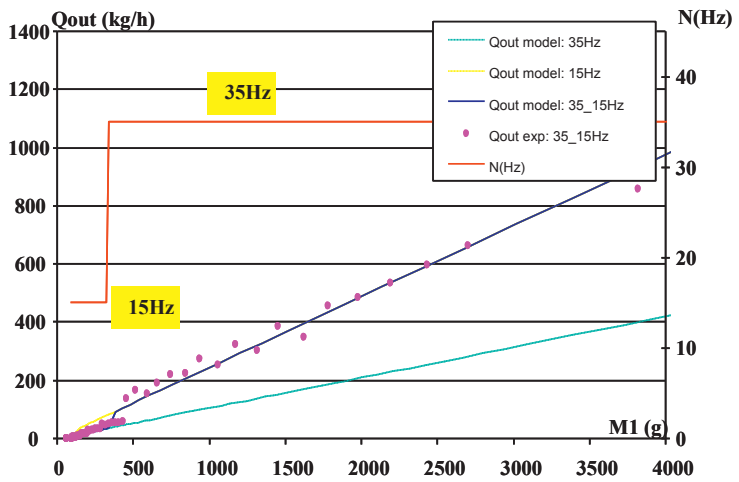

Fig. 12. Comparison of simulated and measured values of $p_{21}$ during the emptying process after a positive step change in rotational speed $N$, on the basis of time change (a) or hold-up change (b).

$\left(p_{21 \max }=0.07\right)$, and the corresponding outflow rate changes linearly with $M_{1}$ according to Eq. (18).

- The next phase begins when $N$ changes from 20 to $40 \mathrm{~Hz}$, at $t=40 \mathrm{~s}$. Immediately after this step change, the value of $p_{21}$ increases to remain stable ( $p_{21}=0.14$ ) as long as $M_{1}$ is higher than $M_{\text {threshold }}$ for this new value of $N$.

- Finally, when $M_{1}$ becomes lower than the threshold mass, the probability increases almost linearly with the hold-up weight, and the outflow rate changes with $M_{1}$ according to a second order polynomial function (Eq. (20)).
The results obtained for the negative step change in rotational speed, while not presented her for clarity reasons, also supports the parameter identification results, and confirms that the probability to leave the mixer depends only on the rotational speed and on the current particle mass in the mixer. The empirical correlations that have been developed in this work seem to be robust enough to describe the dynamics of the emptying process, even when it includes a strong variation on the process variables. In other words, the "history" of the process, does not influence its dynamics, which corresponds to the Markov property. 


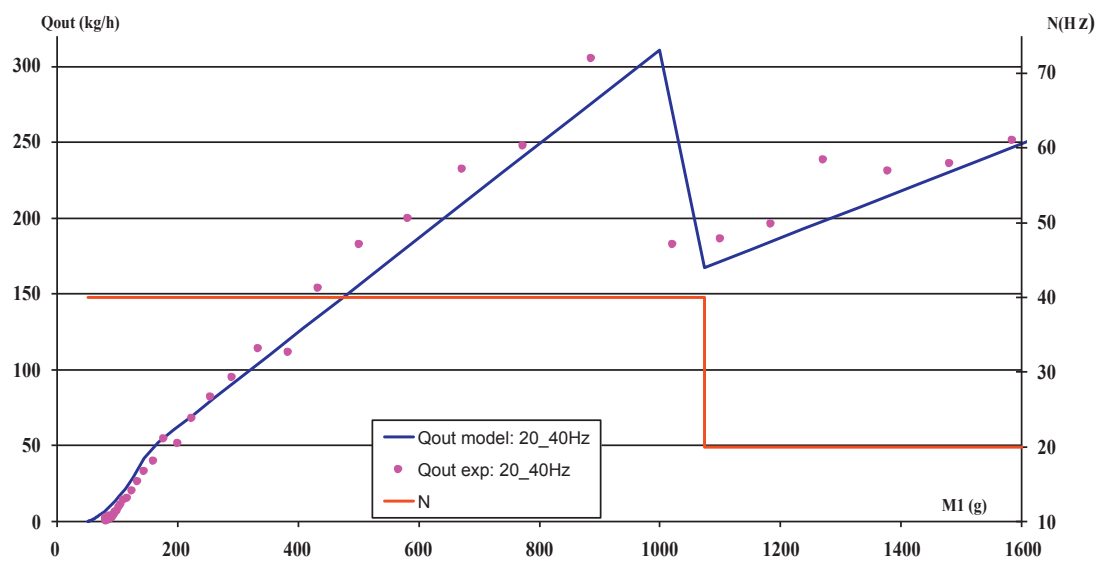

Fig. 13. Simulated and measured evolution of the outflow rate with the hold-up weight $M_{1}$ during a positive step change in rotational speed $N$, focussing on the small masses.

\section{Concluding remarks}

In this study, we have developed a Markov chain approach to represent the dynamics of the emptying process of a continuous powder mixer. The chain is only here to provide a general framework of the problem, and includes correlations obtained from experimental data fitting. The transition matrix only depends on the rotational speed of the stirrer and the hold-up weight, as the chain can either be homogeneous or non-homogeneous during the emptying process. All obtained functional relationships are based on information gathered experimentally from continuous system operating in semi-batch mode, and may serve to the better understanding and modelling of continuous regime.

An important industrial issue is concerned with the eventuality of stopping the feeding system during its filling to avoid perturbation due to low-quality dosage, letting the mixer operate in the meantime. From the present study, it can be argued that, as soon as the hold up weight is above the threshold value, the chain is homogeneous and the mixer may still operate adequately, but with a changed outflow rate. But if the hold up weight passes this limit, the chain becomes non-homogeneous, and the non-linear character of the emptying process may give rise to some fluctuations and perhaps homogeneity loss of the final product, as transition matrices are changing at every step.

This work and the methodology presented also suggest that simple emptying experiments can be run to determine the set of governing parameters, at least for similar mixing geometries and free-flowing powders. This would suffice to elaborate a simple model of global behaviour of a continuous mixer that may be useful for a process engineer, as a first step.

Finally, it may be thought that a number of principles laying behind powder blending in semi-batch mode, or in transitory regimes in general, would play an important role in understanding and modelling the steady-state operation of a continuous system and its process control. Future work from our team will be concentrated on this point.

\section{References}

[1] M. Aoun Habbache, M. Aoun, H. Berthiaux, V. Mizonov, An experimental method and a Markov chain model to describe axial and radial mixing in a hoop mixer, Powder Technology 128 (2002) 159-167.

[2] H. Berthiaux, K. Marikh, V. Mizonov, D. Ponomarev, E. Barantzeva, Modelling continuous powder mixing by means of the theory of Markov chains, Particulate Science and Technology 22 (2004) 379-389.

[3] H. Berthiaux, V. Mizonov, Application of Markov chains in particulate process engineering: a review, The Canadian Journal of Chemical Engineering 82 (6) (2004) 1143-1168.

[4] H. Berthiaux, K. Marikh, C. Gatumel, Continuous mixing of powder mixtures with pharmaceutical process constraints, Chemical Engineering and Processing: Process Intensification 47 (12) (2008) 2315-2322.

[5] S.J. Chen, L.T. Fan, C.A. Watson, The mixing of solid particles in a motionless mixer-a stochastic approach, AIChE Journal 18 (5) (1972) 984-989.

[6] J. Doucet, N. Hudon, F. Bertrand, J. Chaouki, Modeling of the mixing of monodisperse particles using a stationary DEM-based Markov process, Computers and Chemical Engineering 32 (2008) 1334-1341.

[7] L.T. Fan, S.H. Shin, Stochastic diffusion model of non-ideal mixing in a horizontal drum mixer, Chemical Engineering Science 34 (1979) 811-820.

[8] I. Inoue, K. Yamaguchi, Particle motion in a mixer. Mixing in a two dimensional V-type mixer, International Chemical Engineering 10 (3) (1970) 490-497.

[9] F.S. Lai, L.T. Fan, Application of discrete mixing model to the study of mixing of multicomponent solid particles, Industrial \& Engineering Chemistry: Process Design and Development 14 (4) (1975) 403-411.

[10] K. Marikh, H. Berthiaux, V. Mizonov, E. Barantseva, Experimental study of the stirring conditions taking place in a pilot plant continuous mixer of particulate solids, Powder Technology 157 (2005) 138-143.

[11] Y. Oyama, K. Agaki, Studies on the mixing of particulate solids, Kagaku Kogaku (Japan) 20 (1956) 148-154.

[12] D. Ponomarev, V. Mizonov, H. Berthiaux, C. Gatumel, J. Gyenis, E. Barantseva, A 2D Markov chain for modelling powder mixing in alternately revolving static mixers of Sysmix ${ }^{\circledR}$ type, Chemical Engineering and Processing: Process Intensification 48 (2009) 1495-1505.

[13] O. Sudah, D. Coffin-Beach, F. Muzzio, Effects of blender rotational speed and discharge on the homogeneity of cohesive and free-flowing mixtures, International Journal of Pharmaceutics 27 (2002) 57-68.

[14] R. Wang, L.T. Fan, Axial mixing of grains in a motionless Sulzer (Koch) mixer, Industrial \& Engineering Chemistry: Process Design and Development 15 (3) (1976) 381-388.

[15] R. Wang, L.T. Fan, Stochastic modelling of segregation in a motionless mixer, Chemical Engineering Science 32 (1977) 695-701. 